\title{
Kısıntılı ve Tam Sulama Koşullarında Verim ve Lif Kalitesi Bakımından Üstün Ileri Pamuk (Gossypium hirsutum L.) Hatlarının Seleksiyonu
}

\section{Hatice Kübra GÖREN ${ }^{1}$ (D) Hüseyin BAŞAL ${ }^{*}$}

\author{
${ }^{1}$ Aydın Adnan Menderes Üniversitesi, Ziraat Fakültesi, Tarla Bitkileri Bölümü, Aydın
}

Öz: Bu çalışma, $\mathrm{F}_{8}$ generasyonunda pamuk (Gossypium hirsutum L.) döl sıraları arasından verim ve lif kalitesi bakımından üstün ileri pamuk hatlarını belirlemek amacıyla 2018 yılında Aydın Adnan Menderes Üniversitesi Ziraat Fakültesi Tarla Bitkileri deneme alanında augmented deneme desenine uygun olarak; tek bitki döl sıraları ve beş adet kontrol çeşit (Gloria, Flash, DP332, Candia ve Claudia) ile dört tekerrürlü ve sıra uzunluğu $12 \mathrm{~m}$ olacak şekilde damla sulama yöntemi kullanılarak tam (\%100) ve kısıntılı sulama (\%50) koşullarında yürütülmüştür. Çalışma sonucunda elde edilen veriler değerlendirildiğinde; tam sulama koşullarında Carmen $\times$ Nazilli-503 (hat no: 1), DPL-90 x Tamcot-22 (hat no: 10), BA-308 x Carmen (hat no: 38), DPL-90 x Tamcot-22 (hat no: 66) ve ST-373 x DPL-90 (hat no: 72) ileri pamuk hatlarının verim ve lif kalite özellikleri yönünden öne çıktığı gözlemlenmiştir. Kısıntılı sulama koşullarında ise Nazilli-503 x Tamcot-22 (hat no: 6), ST-373 x Carmen (hat no: 23), BA-308 x Nazilli-503 (hat no: 47), BA-308 x Carmen (hat no: 72), ve Ş-2000 x Tamcot-22 (hat no: 90) ileri pamuk hatlarının su stresine dayanıklı veya tolerant olduğu saptanmıştır. Tam ve kısıntılı sulama koşullarına uygun, verim ve lif kalitesi yüksek yeni pamuk çeşitlerinin tescil edilmesi amacıyla seçilmiş ileri pamuk hatları çeşit verim denemelerine alınacaktır.

Anahtar Kelimeler: Diallel melezleme, pamuk ıslahı, su stresi

\section{Selection of Advanced Cotton (Gossypium hirsutum L.) Lines for Yield and Fiber Quality Under Deficit and Full Irrigation Condititons}

\begin{abstract}
This study was carried out at Aydin Adnan Menderes University, Agriculture Faculty Field Crops Experiment fields under drip irrigation system to investigate the response of cotton hybrid populations to water stress in $F_{8}$ generations in accordance with Augmented randomized complete block design. Each lines and five control varieties (Gloria, Flash, DP332, Candia and Claudia) were planted one row and $12 \mathrm{~m}$ long under irrigated (\%100: full irrigation) and water stress (\%50: deficit irrigation) conditions. The result of the study revealed that in $F_{8}$ generation; Carmen $x$ Nazilli-503 (line no: 1), DPL-90 x Tamcot-22 (line no: 10), BA-308 x Carmen (line no: 38), DPL-90 x Tamcot-22 (line no: 66) and ST-373 x DPL-90 (line no: 72) cotton advanced lines exhibited the highest seed cotton yield and fiber quality. As for under deficit water stress condition Nazilli-503 x Tamcot-22 (line no: 6), ST-373 x Carmen (line no: 23), BA-308 x Nazilli-503 (line no: 47), BA-308 x Carmen (line no: 72), and Ş-2000 x Tamcot-22 (line no: 90) were found to be drought resistant or tolerant hybrid populations. In order to register new cotton varieties with high yield and fiber quality suitable for full and limited irrigation conditions, selected cotton lines will be tested for variety yield tests.
\end{abstract}

Keywords: Diallel hybridization, cotton breeding, water stress

\section{GiRiş}

Küresel iklim değişikliğinin etkisi arttıkça, bitkisel üretim için su kaynakları azalmaya devam etmektedir (Barnabas ve ark., 2008). Kuraklık, bitkisel üretimi sınırlayan en önemli çevresel faktörlerden biri haline gelmiştir. Pamuk (Gossypium hirsutum L.) kültür bitkileri içerisinde kuraklığa dayanıklılık yönünden öne çıkmaktadır (Parida ve ark., 2007). Ancak etki süresi ve meydana geldiği fenolojik döneme göre değişmekle birlikte, kuraklık stresi pamukta stomatal kapanmaya bağlı olarak fotosentetik aktivite ve bitki kuru madde paylaşımını olumsuz etkilemektedir (Bota ve ark., 2004; Pettigrew, 2004; Pettigrew ve Gerik, 2007). Kuraklık hem verim hem de lif kalite özelliklerini olumsuz yönde etkilemektedir. Birçok araştırmacı pamuk liflerinin uzamaya başladığı evrede maruz kalınan kuraklığın lif inceliği, lif uzunluğu ve lif dayanıklılığını olumsuz yönde etkilediğini bildirmiştir (McWilliams, 2004; Mert, 2005; Başal ve ark., 2009).

Bugünün iklim şartlarında, ülkemizde küresel iklim değişikliği su kaynaklarının azalması, sıcak hava dalgalarının oluşması, sellerdeki artış, kuraklık ve tarımda verimliliğin düşmesi olarak ortaya çıkmaktadır (Bayraç ve Doğan, 2016). İklim koşullarının değişkenliği göz ardı edilse bile, sadece nüfus artışına bağlı olarak 2050 yılında su kıtlığı çeken ülkelerden biri olacağımız öngörülmektedir (Kadıoğlu ve ark., 2017). IPCC Dördüncü Değerlendirme Raporu'na göre, 21. yüzyılın sonuna doğru yaklaşıldıkça Türkiye'de yılık ortalama sıcaklıkların bugüne oranla yaklaşık 3 ile $5{ }^{\circ} \mathrm{C}$ artacağı tahmin edilmektedir. Pamuk üretimimizin yapıldığı Ege, Güneydoğu Anadolu ve Çukurova-Antalya bölgeleri, Türkiye'de kuraklıktan en yoğun etkilenecek bölgeler arasındadır. Toplam pamuk üretiminin yaklaşık \%60'ının

*Sorumlu Yazar: hbasal@adu.edu.tr. Bu çalışma Aydın Adnan Menderes Üniversitesi, Bilimsel Araştırma Projeleri Birimi tarafından desteklenmiştir (Proje No: ZRF-18028).

Geliş Tarihi: 12 Mart 2020

Kabul Tarihi: 9 Aralık 2020 
yapıldığı Güneydoğu Anadolu bölgesinde ise sıcaklık artışının daha yüksek olacağı öngörülürken; üretimin geri kalanının yapıldığı Ege bölgesi (\%20) ve Akdeniz ikliminin etkili olduğu Çukurova - Antalya bölgelerinde (\%19) sıcaklık artışının daha düşük kalacağı fakat \%30'lara ulaşan oranlarda yağışta azalmaların olacağı öngörülmektedir (IPCC, 2013).

Uzun dönemde küresel iklim değişikliğinin ve özellikle kuraklık stresinin pamuk üretimimiz üzerine yapacağı olumsuz etkileri azaltmak amacıyla, yüksek verim kapasitesine sahip, su stresine dayanıklı ve tohum temininde dışa bağımlı olmadan yerli pamuk çeşitlerinin geliştirilmesi zorunlu hale gelmiştir. Bu nedenle bu çalışma; i) Kısıntlı sulama uygulaması altında su stresine tolerant homozigot hatların ve ii) Tam sulama uygulaması altında ise verimi ve lif kalitesi yüksek homozigot hatların seçilmesi amacıyla yürütülmüştür.

\section{MATERYAL VE YÖNTEM}

\section{Materyal}

$\mathrm{Bu}$ çalışmanın materyalini oluşturan popülasyonu, Aydın Adnan Menderes Üniversitesi Ziraat Fakültesi Tarla Bitkileri deneme alanında, 2009 yılında, önceki araştırmalarda kuraklığa dayanıklı olduğu gözlenen 8 adet pamuk çeşidinin (BA 308, Carmen, DPL 90, Nazilli 503, ST 373, Şahin 2000, Tamcot Sphinx ve Tamcot 22) yarım diallel melezleme yöntemine göre melezlenmesiyle elde edilen 28 adet melez kombinasyonu oluşturmaktadır. 2010 yılında $F_{1}$ oluşturulmuş, 2011 yılında tam sulama (\%100) ve kısıntlı sulama (\%50) altında yetiştirilen $\mathrm{F}_{2}$ generasyonundaki melez kombinasyonların her birinden tek koza alınarak bulk yapılmış ve $F_{3}$ generasyonu oluşturulmuştur. Bundan sonraki süreçte tek bitki seleksiyonuna $F_{3}$ generasyonundan $\mathrm{F}_{7}$ generasyonuna kadar tam ve kısıntlı sulama koşullarında ayrı ayrı devam edilmiştir. 2017 yılının sonunda; tam sulama şartlarında öne çıkan 76, kısıtlı sulama şartlarında öne çıkan 96 adet tek bitki $F_{8}$ generasyonuna aktarılmış ve bu çalışmanın materyalini oluşturmuştur.

\section{Yöntem}

Çalışma Aydın Adnan Menderes Üniversitesi Ziraat Fakültesi Tarla Bitkileri deneme alanında kısıtlı (\%50) ve tam (\%100) sulama şartları altında yürütülmüştür. Çalışma tam sulama altında 96 adet, kısıtlı sulama altında ise 72 adet tek bitki döl sıraları ve beş kontrol çeşit (Gloria, Flash, DP332, Candia ve Claudia) ile beraber augumented deneme deseninde, sıra arası $70 \mathrm{~cm}$, sıra uzunluğu $12 \mathrm{~m}$ ve 4 tekerrürlü olarak deneme mibzeri ile 27.04.2018 tarihinde ekilmiştir. Denemedeki her genotip tekrarsız olarak tek sıra, kontrol çeşitler ise her blokta bir defa ekilmiştir. ilk çapalama işleminden sonra sıralar seyreltilmiş ve sonraki çapayla birlikte tekleme yapılarak her bir sırada ortalama 60-65 bitki bırakılmıştır. Denemedeki gözlemler uygun dönemlerde 10 200 bitki üzerinden alınmıştır. Denemede sulama seviyelerinin daha kolay ayarlanabilmesi açısından damla sulama yöntemi tercih edilmiştir. Deneme parsellerinin sulanması için gerekli olan sulama su yer altı su kaynağından (artezyen) temin edilmiştir. Deneme parsellerinde toprak neminin izlenmesi; gravimetrik yönteme uygun olarak 90 cm'ye kadar üç toprak katmanından alınan örneklerde nem içeriği yüzde (\%) olarak hesaplanmıştır. Belirlenen katmanlardan Petersen ve Calvin (1965)'de belirlenen esaslara göre her sulamadan önce bozulmuş toprak örnekleri alınmıştır. Sulama zamanı tam sulama uygulanan parsellerdeki kullanılabilir su miktarının \%50'ye düştüğünü an olarak belirlenmiştir. Tam sulama uygulanan parsellere belirlenen nem açığının tamamı, kısıtlı sulama uygulanan parsellere ise yarısı kadar su verilmiştir. Deneme süresince tam sulama koşullarına 464 mm, kısıtlı sulama koşullarına ise $232 \mathrm{~mm}$ su verilmiştir.

Lif teknolojik analizler ELiDAŞ Firmasında High Volume Instrument ( $\mathrm{HVI}$ ) aleti yardımı ile belirlenmiş, elde edilen tüm veriler JMP 5.0.1 istatistik paket program yardımı ile değerlendirilmiş, gruplamalar ise LSD (0.05) çoklu karşılaştırma yöntemine göre yapılmıştır.

\section{BULGULAR VE TARTIŞMA}

$\mathrm{F}_{8}$ generasyonuna ait genotiplerin tam ve kısıtlı sulama şartları altında incelenen özelliklerine ait varyans analiz sonuçları sırasıyla, Çizelge 1 ve 2'de verilmiştir. Tam (\%100) sulama koşullarında lif inceliği dışında kalan özellikler arasında, kısıtlı sulama (\%50) koşullarında ise incelenen bütün özellikler bakımından pamuk döl sıraları arasındaki farklılığın önemli olduğu sonucuna varılmıştır.

Tam (\%100) ve kısıtlı (\%50) sulama koşullarında, $F_{8}$ generasyonuna ait pamuk döl sıralarının incelenen özellikler bakımından ortalama değerlerinin karşılaştırılması

Denemeye alınan $\mathrm{F}_{8}$ generasyonuna ait pamuk melez döl sıralarının tam sulama (\%100) koşullarında kütlü pamuk verimi $(\mathrm{kg} / \mathrm{da})$, çırçır randımanı (\%), bitkide koza sayısı (adet/bitki), lif uzunluğu ( $\mathrm{mm})$, lif kopma dayanıklılık (gr/tex) ve lif incelik (mic.) değerleri Çizelge 3'de, kısıtlı sulama koşullarında (\%50) saptanan ortalama değerler Çizelge 4'de verilmiştir. Dergide sayfa sınırlaması olduğu için sulama uygulamalarının kütlü pamuk verimi bakımından yalnızca ilk ve son on sırada olan genotiplerin incelenen özellikler bakımından ortalamaları verilebilmiştir.

İleri pamuk hatları en önemli seleksiyon kriteri olan kütlü pamuk verimi bakımından incelendiğinde; tam sulama koşullarında, en yüksek verim $(712.4 \mathrm{~kg} / \mathrm{da}) 1$ numaralı (Carmen x Nazilli-503), en düşük verim ise (399.6 kg/da) 46 (ST-373 x Ş-2000) numaralı hattan elde edilmiştir. Kontrol çeşitler arasında Gloria $456.3 \mathrm{~kg} / \mathrm{da}$ verimi ile ilk sırada, Flash 396.9 kg/da verimi ile son sırada yer almıştır. Melez döl sıraları kütlü pamuk verimi bakımından kontrol çeşitler 
Çizelge 1. $F_{8}$ generasyonuna ait pamuk döl sıralarının tam sulama (\%100) koşullarında incelenen özelliklere ait varyans analiz sonuçları.

\begin{tabular}{llllllll}
$\begin{array}{l}\text { Varyasyon } \\
\text { Kaynakları }\end{array}$ & SD & BKS & ÇR & Verim & LU & LKD & Li \\
\hline Tekerrür & 3 & 0.40 & 1.79 & 1411 & 1.23 & 8.13 & 0.273 \\
Kontrol & 5 & 24.18 & 15.76 & 45125 & 5.87 & 19.66 & 0.015 \\
Genotip & 75 & $14.89^{* *}$ & $4.89^{* *}$ & $5267^{*}$ & $2.48^{* *}$ & $7.74^{* *}$ & 0.085 \\
Hata & 12 & 2.02 & 1.25 & 2207 & 0.95 & 3.52 & 0.059 \\
Genel & 95 & & & & & &
\end{tabular}

SD: Serbestlik derecesi, BKS: Bitkide koza sayısı ÇR: Çırçır randımanı, Verim: Kütlü pamuk verimi, LU: Lif uzunluğu, LKD: Lif kopma dayanıklılığı, Lì: Lif inceliği.

*: 0,05 olasılık seviyesinde önemli, **: 0,01 olasılık seviyesinde önemli.

Çizelge 2. $\mathrm{F}_{8}$ generasyonuna ait pamuk döl sıralarının kısıtlı sulama (\%50) koşullarında incelenen özelliklere ait varyans analiz sonuçları.

\begin{tabular}{llllllll}
\hline $\begin{array}{l}\text { Varyasyon } \\
\text { Kaynakları }\end{array}$ & SD & BKS & ÇR & Verim & LU & LKD & Li \\
\hline Tekerrür & 3 & 11.8 & 5.86 & 10610 & 2.83 & 1.54 & 0.168 \\
Kontrol & 5 & 5.86 & 27.28 & 10247 & 9.03 & 23.9 & 0.204 \\
Genotip & 95 & $3.89^{*}$ & $2.55^{* *}$ & $4648^{*}$ & $2.57^{* *}$ & $9.15^{* *}$ & $0.079^{*}$ \\
Hata & 12 & 1.85 & 1.11 & 1945 & 0.98 & 3.36 & 0.022 \\
Genel & 115 & & & & & & \\
\hline
\end{tabular}

SD: Serbestlik derecesi, BKS: Bitkide koza sayısı ÇR: Çırçır randımanı, Verim: Kütlü pamuk verimi, LU: Lif uzunluğu, LKD: Lif kopma dayanıkılığı, Li: Lif inceliği.

*: 0,05 olasılık seviyesinde önemli, **: 0,01 olasılık seviyesinde önemli.

ile karşılaştırıldığında; 44 adet döl sırasının en yüksek verim değerine sahip kontrol çeşidinden (Gloria) daha yüksek verim değerlerine ulaştıkları saptanmıştır (Çizelge 3). Kısıtlı (\%50) sulama koşullarında tek bitki döl sıralarının ortalama kütlü pamuk verim değerleri $581.1 \mathrm{~kg} / \mathrm{da}$ (ST-373 x Ş-2000, hat no:48) ile $181.5 \mathrm{~kg} / \mathrm{da}$ (BA-308 × Carmen, hat no:7) arasında değişiklik göstermiştir. Gloria $382.6 \mathrm{~kg} / \mathrm{da}$ ile kontrol pamuk çeşitleri arasındaki en yüksek verim değerine sahip olan çeşit olarak gözlenmiştir. Kütlü pamuk verimi bakımından en yüksek kontrol çeşitten daha yüksek verim değerlerine sahip 60 adet genotip tespit edilmiştir (Çizelge 4).

Denemede yer alan pamuk genotiplerinin tam ve kısıtlı sulama şartları altında ortalama kütlü pamuk verim değerleri karşılaştırıldığında; Kısıtlı sulama uygulamasının kütlü pamuk veriminde $\% 27$ oranında bir azalmaya neden olduğu gözlemlenmiştir (Çizelge 3 ve 4). Daha önce yapılan çalışmalarda kuraklık stresinin şiddetine bağlı olarak ortaya çıkan verim kaybının \%12 ile \%55 arasında değiştiği ortaya konmuştur (Basal ve ark., 2009; Karademir ve ark., 2011; Asadi ve ark., 2011; Papastylianou ve Argyrokastritis, 2014, $\mathrm{Hu}$ ve ark., 2018a). Shaareff ve ark., (2018), su stresi koşullarında fotosentez ürünü olan asimilatların organlar arasındaki paylaşımının farklı olduğu, en fazla asimilat birikiminin bitkinin kök kısmında daha sonra yapraklarda en düşük oranda birikimin ise kozalarda olduğunu bildirmiştir. Bunun sonucunda birim alandaki koza sayısı ve koza ağırlığının azalması verimde düşüşlere neden olduğunu ortaya koymuşlardır.

Optimum (tam) sulama koşullarında en düşük çırçır randımanı \%32.7 ile Nazilli-503 x Ş-2000 (hat no: 28), en yüksek çırçır randımanı \% 43.1 ile DPL-90 x Tamcot-22 (hat no: 10) melezinde gözlenmiştir. Kontrol pamuk çeşitleri arasında en yüksek çırçır randımanı \%42.5 ile DP 332 çeşidinde, en düşük çırçır randımanı ise \%38.9 ile Flash pamuk çeşidinde gözlenmiştir. İncelenen özellik bakımından hatlar ile kontrol çeşitler karşılaştırıldığında; sadece DPL-90 x Tamcot-22 (hat no: 10) hattının en yüksek değere sahip kontrol (DP 332) çeşidinden daha yüksek değere sahip olduğu gözlenmiştir (Çizelge 3). Hatların kısıtlı sulama (\%50) uygulamasında çırçır randımanı değerlerine bakıldığında, pamuk ileri hatlarının çırçır randıman değerleri \%42.8 (Nazilli-503 x Tamcot-22, hat no: 6) ile \%35.7 (BA-308 x Carmen, hat No: 73) arasında, kontrol çeşitlerin çırçır randıman değerlerinin \%41.2 (Flash) ile \%43.7 (DP332) arasında değiştiği gözlenmiştir. DP332 kontrol çeşidinden daha yüksek çırçır randıman değerine sahip pamuk hattı gözlenmemiştir (Çizelge 4).

Kısıtlı sulama şartlarında hatların ortalama çırçır randımanı değeri \%39.5; tam sulama şartlarında ise \%39.2 olarak bulunmuştur. Bulunan bu sonuca paralel olarak Şahin, (2000) ile Hussein (2011), yürüttükleri çalışmalarında kısıtlı sulamanın çırçır randımanını etkilemediği sonucuna varırken, Ertek ve Kanber, (2003) ile Başal ve ark., (2009) ise tam sulama uygulamalarının olgunluk süresini etkilediğinden dolayı kısıtlı sulamanın çırçır randımanını arttırdığını bildirmişlerdir. Hu ve ark. (2018b), su stres seviyesinin artışı ile birlikte birim tohum yüzeyinde lif sayısı ve lif uzunluğunun azalmasına karşın, her bir lifin ağırlığının artması sonucunda da çırçır randıman değerinin arttığını ortaya koymuştur. 
Çizelge 3. Tam sulama (\%100) koşullarında $\mathrm{F}_{8}$ generasyonuna ait pamuk döl sıralarının incelenen özellikler bakımından ortalama değerleri

\begin{tabular}{|c|c|c|c|c|c|c|c|}
\hline $\begin{array}{l}\text { Hat } \\
\text { No }\end{array}$ & $\begin{array}{l}\text { Melez } \\
\text { Kombinasyonu }\end{array}$ & $\begin{array}{l}\text { KPV } \\
\text { (kg/da) }\end{array}$ & $\begin{array}{l}\text { ÇR } \\
(\%)\end{array}$ & $\begin{array}{l}\text { BKS } \\
\text { (adet/bitki) }\end{array}$ & $\begin{array}{l}\text { LU } \\
(\mathrm{mm})\end{array}$ & $\begin{array}{l}\text { LKD } \\
\text { (gr/tex) }\end{array}$ & $\begin{array}{l}\text { Li } \\
\text { (Mic.) }\end{array}$ \\
\hline 1 & Carmen X Nazilli-503 & 712.4 & 39.0 & 24.1 & 31.7 & 31.8 & 4.6 \\
\hline 38 & BA-308 X Carmen & 700.6 & 39.1 & 23.1 & 30.9 & 30.6 & 4.3 \\
\hline 6 & BA-308 X Carmen & 698.8 & 38.7 & 28.7 & 29.9 & 31.9 & 4.8 \\
\hline 72 & ST-373 X DPL-90 & 692.2 & 33.8 & 22.4 & 29.3 & 31.1 & 5.1 \\
\hline 66 & DPL-90 X Tamcot-22 & 677.1 & 43.0 & 22.4 & 30.9 & 36.4 & 4.9 \\
\hline 19 & Carmen X Ş-2000 & 660.8 & 38.2 & 21.4 & 28.8 & 31.6 & 4.7 \\
\hline 13 & DPL-90 X Tamcot-22 & 650.3 & 42.0 & 24.8 & 29.1 & 31.8 & 5.0 \\
\hline 74 & ST-373 X Ş-2000 & 648.1 & 42.8 & 23.7 & 34.3 & 32.9 & 4.7 \\
\hline 67 & DPL-90 X Tamcot-22 & 643.2 & 42.8 & 22.9 & 30.9 & 33.3 & 4.9 \\
\hline 68 & DPL-90 X Tamcot-22 & 639.2 & 42.7 & 23.9 & 29.3 & 32.3 & 4.6 \\
\hline 10 & DPL-90 X Tamcot-22 & 601.0 & 43.1 & 17.8 & 29.5 & 36.1 & 5.0 \\
\hline 52 & BA-308 X Carmen & 458.6 & 38.9 & 9.5 & 28.9 & 33.3 & 5.3 \\
\hline 51 & BA-308 X Carmen & 457.9 & 40.6 & 9.8 & 32.3 & 32.7 & 4.5 \\
\hline 32 & BA-119 x SJ-U86 & 451.4 & 38.8 & 11.0 & 29.9 & 34.7 & 4.5 \\
\hline 58 & Carmen X DPL-90 & 449.6 & 37.1 & 9.4 & 33.5 & 36.3 & 4.4 \\
\hline 42 & Nazilli-503 X DPL-90 & 440.0 & 38.7 & 12.5 & 30.8 & 31.7 & 5.0 \\
\hline 23 & ST-373 X Ş-2000 & 435.4 & 37.4 & 9.6 & 28.8 & 28.2 & 5.1 \\
\hline 28 & Nazilli-503 X Ş-2000 & 430.8 & 32.7 & 13.7 & 29.1 & 29.8 & 4.9 \\
\hline 31 & TamctSphinxxTamcot22 & 403.7 & 38.9 & 12.2 & 30.8 & 30.8 & 4.2 \\
\hline 65 & Carmen X DPL-90 & 400.2 & 41.5 & 13.3 & 31.0 & 31.9 & 4.5 \\
\hline 46 & ST-373 X Ş-2000 & 399.6 & 36.3 & 9.9 & 30.9 & 32.1 & 4.6 \\
\hline \multicolumn{2}{|c|}{ Hat Ortalaması } & 552.5 & 39.2 & 17.4 & 30.6 & 32.3 & 4.7 \\
\hline K1 & Gloria & 456.3 & 39.4 & 16.1 & 30.8 & 37.3 & 4.7 \\
\hline K2 & Flash & 396.9 & 38.9 & 11.0 & 30.8 & 33.5 & 4.8 \\
\hline K3 & DP332 & 437.3 & 42.5 & 14.0 & 28.5 & 33.7 & 4.8 \\
\hline K4 & Candia & 414.0 & 42.2 & 15.2 & 29.1 & 33.7 & 4.7 \\
\hline K5 & Claudia & 428.9 & 39.8 & 15.0 & 31.3 & 36.3 & 4.8 \\
\hline \multicolumn{2}{|c|}{ Kontrol Çeşit Ortalaması } & 426.7 & 40.6 & 14.2 & 30.1 & 34.9 & 4.8 \\
\hline \multicolumn{2}{|c|}{ Genel ortalama } & 528.3 & 39.4 & 16.8 & 30.5 & 32.8 & 4.7 \\
\hline \multicolumn{2}{|c|}{$\operatorname{EKÖF}_{(0.05)}$} & 66.4 & 1.58 & 1.58 & 1.38 & 2.65 & ÖD \\
\hline
\end{tabular}

KPV: Kütlü pamuk verimi kg/da), ÇR: Çırçır randımanı (\%), ), BKS: Bitkide koza sayısı (adet/bitki), LU: Lif uzunluğu (mm), LKD: Lif kopma dayanıklılığı (g/tex), Li: Lif inceliği (Mic.). EKÖF: 0,05 olasılık seviyesinde en küçük önemli farklılık.

Kısıtlı sulama şartlarında hatların ortalama çırçır randımanı değeri \%39.5; tam sulama şartlarında ise \%39.2 olarak bulunmuştur. Bulunan bu sonuca paralel olarak Şahin, (2000) ile Hussein (2011), yürüttükleri çalışmalarında kısıtlı sulamanın çırçır randımanını etkilemediği sonucuna varırken, Ertek ve Kanber, (2003) ile Başal ve ark., (2009) ise tam sulama uygulamalarının olgunluk süresini etkilediğinden dolayı kısıtlı sulamanın çırçır randımanını arttırdığını bildirmişlerdir. Hu ve ark. (2018b), su stres seviyesinin artışı ile birlikte birim tohum yüzeyinde lif sayısı ve lif uzunluğunun azalmasına karşın, her bir lifin ağırlığının artması sonucunda da çırçır randıman değerinin arttığını ortaya koymuştur. 


\begin{tabular}{|c|c|c|c|c|c|c|c|}
\hline $\begin{array}{l}\text { Hat } \\
\text { No }\end{array}$ & $\begin{array}{l}\text { Melez } \\
\text { Kombinasyonu }\end{array}$ & KPV (kg/da) & $\begin{array}{l}\text { ÇR } \\
(\%)\end{array}$ & $\begin{array}{l}\text { BKS } \\
\text { (adet/bitki) }\end{array}$ & $\begin{array}{l}\text { LU } \\
(\mathrm{mm})\end{array}$ & $\begin{array}{l}\text { LKD } \\
\text { (gr/tex) }\end{array}$ & $\begin{array}{l}\text { Li } \\
\text { (Mic.) }\end{array}$ \\
\hline 48 & ST-373 X Ş-2000 & 581.1 & 40.6 & 13.6 & 29.1 & 27.5 & 4.8 \\
\hline 49 & ST-373 X Carmen & 578.5 & 39.3 & 13.6 & 29.3 & 32.3 & 4.7 \\
\hline 75 & BA-308 X Carmen & 546.6 & 40.8 & 14.0 & 27.9 & 30.4 & 5.1 \\
\hline 72 & BA-308 X Carmen & 537.5 & 38.3 & 15.2 & 32.0 & 36.3 & 5.1 \\
\hline 77 & BA-308 X DPL-90 & 536.8 & 42.2 & 14.5 & 28.6 & 29.4 & 4.2 \\
\hline 90 & Ş-2000 X Tamcot-22 & 530.0 & 40.4 & 13.5 & 29.1 & 33.5 & 5.2 \\
\hline 47 & BA-308 X Nazilli-503 & 527.3 & 38.9 & 13.2 & 31.5 & 30.1 & 5.0 \\
\hline 46 & Nazilli-503 XTamcot22 & 520.8 & 39.8 & 12.0 & 28.0 & 32.2 & 4.2 \\
\hline 73 & BA-308 X Carmen & 508.7 & 35.7 & 13.8 & 32.7 & 34.6 & 4.8 \\
\hline 6 & Nazilli-503 XTamcot22 & 499.4 & 42.8 & 10.6 & 30.0 & 31.7 & 4.8 \\
\hline 23 & ST-373 X Carmen & 499.3 & 39.3 & 13.1 & 29.6 & 34.6 & 5.1 \\
\hline 88 & BA-308 X Nazilli-503 & 321.8 & 40.5 & 9.9 & 30.0 & 32.6 & 4.9 \\
\hline 71 & BA-308 X Carmen & 314.7 & 41.2 & 8.2 & 31.4 & 37.2 & 4.9 \\
\hline 87 & BA-308 X Nazilli-503 & 312.0 & 40.7 & 9.9 & 30.1 & 32.9 & 4.9 \\
\hline 20 & ST-373 X Carmen & 305.2 & 40.8 & 9.1 & 28.2 & 34.4 & 5.1 \\
\hline 10 & ST-373 X Carmen & 304.1 & 41.1 & 6.6 & 31.0 & 30.2 & 4.4 \\
\hline 82 & BA-308 X Nazilli-503 & 303.9 & 37.1 & 10.2 & 31.1 & 35.0 & 4.9 \\
\hline 59 & ST-373 X Carmen & 283.3 & 39.2 & 8.6 & 29.5 & 35.4 & 5.1 \\
\hline 8 & BA-308 X Carmen & 273.3 & 38.9 & 5.9 & 31.0 & 32.3 & 4.4 \\
\hline 95 & BA-308 X Nazilli-503 & 240.1 & 38.4 & 7.4 & 33.1 & 32.8 & 4.3 \\
\hline 7 & BA-308 X Carmen & 181.5 & 38.1 & 5.0 & 30.0 & 32.9 & 5.1 \\
\hline Hat $\mathrm{C}$ & laması & 403.5 & 39.5 & 10.6 & 29.9 & 32.6 & 4.9 \\
\hline K1 & Gloria & 382.6 & 41.3 & 10.6 & 28.9 & 36.8 & 5.0 \\
\hline K2 & Flash & 365.9 & 41.2 & 9.2 & 28.5 & 32.7 & 5.4 \\
\hline K3 & DP332 & 373.7 & 43.7 & 9.5 & 27.6 & 31.2 & 4.8 \\
\hline K4 & Candia & 360.8 & 43.0 & 9.4 & 27.6 & 32.3 & 5.1 \\
\hline K5 & Claudia & 303.1 & 41.3 & 8.5 & 30.0 & 35.9 & 5.0 \\
\hline \multicolumn{2}{|c|}{ Kontrol Çeşit Ortalaması } & 357.2 & 42.1 & 9.4 & 28.5 & 33.8 & 5.1 \\
\hline \multicolumn{2}{|c|}{ Genel ortalama } & 401.3 & 39.6 & 10.5 & 29.8 & 32.7 & 4.9 \\
\hline EKÖF & & 62.3 & 1.49 & 1.92 & 1.40 & 2.59 & 0.21 \\
\hline
\end{tabular}

KPV: Kütlü pamuk verimi kg/da), ÇR: Çırçır randımanı (\%), ), BKS: Bitkide koza sayısı (adet/bitki), LU: Lif uzunluğu (mm), LKD: Lif kopma dayanıklıı̆̆ı (g/tex), Li: Lif inceliği (mic.). EKÖF: 0,05 olasılık seviyesinde en küçük önemli farklıık.

Tam sulama koşullarında pamuk hatlarının bitkide ortalama koza sayısı 9.4 adet/bitki (hat no: 58, Carmen x DPL-90) ile 28.7 adet/bitki (hat no:6, BA-308 x Carmen) arasında, kontrol çeşitlerde ise 11.0 adet/bitki (Flash) ile 16.1 adet/bitki (Gloria) arasında değiştiği tespit edilmiştir. Yapılan karşılaştırma sonucunda 24 adet melez döl sıralarının kontrol çeşitlerden istatiksel anlamda daha yüksek koza sayısına sahip oldukları belirlenmiştir (Çizelge 3). Su stresinin (\%50 kısıtlı sulama) uygulandığı koşullarda en düşük koza sayısı 5.0 adet/bitki ile BA-308 x Carmen (hat no 7), en yüksek koza sayısı 15.2 adet/bitki ile BA-308 x
Carmen (hat no: 72) melez döl sırasında bulunmuştur. Kontrol çeşitlerden Gloria 10.6 adet/bitki koza sayısı değeri ile ilk sırada yer almıştır. Bitkide koza sayısı bakımından 14 adet pamuk hattının Gloria çeşidinden daha fazla kozaya sahip olduğu belirlenmiştir (Çizelge 4). Bitkide koza sayısı (adet/bitki) için kısıtlı ve tam sulama uygulamalarına ait genel ortalamalar karşılaştırıldığında; kısıtlı sulamanın bitkide koza sayısını \%39.1 oranında azalttığı tespit edilmiştir (Çizelge 3 ve 4). Daha önce yapılan birçok çalışma bu çalışmada olduğu gibi kuraklık stresinin koza sayısını önemli oranda düşürdüğünü ortaya koymuştur (McMichael 
ve Hesketh, 1982; Guinn ve Mauney, 1984; Gerik ve ark., 1996; Pettigrew, 2004). Kuraklık stresinin pamukta, stomatal kapanmaya bağlı olarak fotosentetik aktivite ve bitki kuru madde paylaşımını olumsuz etkilediği, bitkideki yaprak alanı gelişimini yavaşlattığı, kuru madde paylaşımında ki farklılıklara neden olduğu ve en düşük asimilat birkiminin kozalarda olması sonucunda koza silkmesinin artması ile birlikte bitkide koza sayısının düştüğünü bildirmişlerdir (Lokhande ve Reddy, 2014; Shareef ve ark., 2018; Wang ve ark., 2016).

Tam sulama koşullarında pamuk genotiplerinin lif uzunluk değerleri $28.8 \mathrm{~mm}$ (Carmen x Ş-2000, hat no: 19 ve ST $373 \mathrm{X}$ Ş-2000, hat no.: 23) ile $34.3 \mathrm{~mm}$ (ST-373 X Ş-2000, hat no: 74) arasında değişmiştir. Kontrol çeşitler arasında en düşük lif uzunluğu (28.5 mm) DP332, en yüksek lif uzunluğu (31.3 $\mathrm{mm}$ ) Claudia çeşidinde saptanmıştır. İleri pamuk hatları arasında sekiz adet ileri hattın Claudia kontrol çeşidinden daha uzun liflere sahip olduğu görülmüştür (Çizelge 3). Kısıtlı sulama (\%50) koşullarında ise lif uzunluk değerleri $27.9 \mathrm{~mm}$ (BA-308 X Carmen, hat no: 75) ile $33.1 \mathrm{~mm}$ (BA308 X Nazilli-503 hat no: 95) arasında, kontrol olarak kullanılan pamuk çeşitlerinin lif uzunluk değerleri ise 27.6 mm (DP 332 ve Candia) ile $30.0 \mathrm{~mm}$ (Claudia) arasında değişmiştir. Melez döl sıraları ile en yüksek lif uzunluğuna sahip kontrol çeşit Claudia arasındaki farkın önemli olduğu, 9 adet hattın lif uzunluk değerlerinin Claudia kontrol çeşidinin lif uzunluk değerinden daha yüksek olduğu bulunmuştur (Çizelge 4).

Su stresinin genotiplerin ortalama lif uzunluğunu \%2.28 oranında azalttığı saptanmıştır (Çizelge 3 ve 4). Bulunan sonuç önceki çalışmalar ile paralellik göstermektedir. (Basal ve ark., 2009; Price, 2009; Hussein ve ark., 2011; Cave, 2013; Ulu ve Başal, 2018; Tang ve ark., 2017). Koza içinde tohum ve lifler aynı fotosentez ürünü kaynağından beslendiği için ikisi arasında rekabetin ortaya çıktığı, ancak fotosentez ürününün liflere oranla tohumda daha fazla birikmesinin lif kalitesini olumsuz etkilediği bildirilmiştir. (Kloth ve Turley 2010; Shareef ve ark., 2018). Tang ve ark. (2017), su stresinin invertaz ve sukroz sentez aktivitelerini azaltması sonucunda heksoz konsantrasyonun düşmesi lif uzamasını olumsuz etkilediği ortaya koymuştur. Gao ve ark. (2020), orta ve şiddetli kuraklık koşullarının, sükroz içeriği ve sükroz sentaz (SuSy) aktivitesini düşürdüğü bunun da düşük turgor basıncına neden olarak lif uzunluğunu azalttığını bildirmiştir.

Ileri pamuk hatlarının tam sulama koşullarında lif dayanıklılık değerlerinin $28.2 \mathrm{~g} /$ tex ile (hat no: $23, \mathrm{ST}-373 \mathrm{x}$ Ş-2000) $36.4 \mathrm{~g} /$ tex (hat no: 66, DPL-90 x Tamcot-22) arasında olduğu saptanmıştır. İncelenen özellik bakımından, en yüksek değer $37.3 \mathrm{~g} /$ tex ile Gloria, en düşük değer 33.5 g/tex ile Flash kontrol çeşidinde tespit edilmiştir. Ileri pamuk hatları arasında Gloria kontrol pamuk çeşidinden daha yüksek lif kopma değerine sahip hat olmadığı gözlenmiştir. Kısıtlı sulama koşullarında, $36.3 \mathrm{~g} /$ tex ile BA308 x Carmen (hat no: 72) pamuk hattı ilk, $27.5 \mathrm{~g} / \mathrm{tex}$ ile değeri ile ST-373 X Ş-2000 (hat no: 48) melez hattının son sırada yer aldığı tespit edilmiştir. Kontrol çeşitler ise arasında en yüksek lif kopma değeri 36.8 g/tex ile Gloria da tespit edilmiştir. Yapılan analiz sonucunda sadece ST-373 x Carmen (hat no: 55) döl sırasının Gloria dan daha sağlam lifler üretebildiği gözlenmiştir.

Pamuk ileri hatlarının genel ortalamaları karşılaştırıldığında, kısıtlı (\%50) sulamanın lif kopma dayanıklılığını \%0.92 oranında düşürdüğü belirlenmiştir (Çizelge 3 ve 4). Çiçeklenmeden 24 gün sonra, selüloz birikimi yoluyla lif mukavemeti oluşumunun en kritik dönemi olan kalınlaşma dönemine geçer. Lifin kalınlaşma süreci, biriken selülozun miktarına ve kalitesine bağlı olduğu (Pettigrew, 2001), sükroz tarafından selüloz birikimi için sağlanan UDPG (UDPG; uridine diphosphate glucose) oranının su stresi altında düştüğü ve daha fazla kalloz sentezlenmeye başladığı (Babb ve Haigler, 2001; Gao ve ark., 2020) ve kozaların sükroz / kalloz oranındaki değişimler selülozun birikme oranını değiştirerek lif mukavemetini olumsuz yönde etkilediği bildirilmiştir (Zhang ve ark., 2007). Bununla beraber; Basal ve ark. (2009), Karademir ve ark. (2011), ve Rai (2011) yaptıkları çalışmalarda su stresinin lif dayanıklılığını olumsuz yönde etkilediğini, Papastylianou ve Argyrokastritis (2014) ise lif kopma dayanıklılığının su stresine karşı verdiği tepkilerin düzensiz olduğunu aktarmışlardır.

Lif inceliği (mikroner değeri) bakımından tam sulama uygulamasında pamuk genotipleri arasında önemli bir farklılık saptanmamıştır. Lif inceliği bakımından pamuk döl sıraları değerlendirildiğinde; en ince lif 4.2 mic değeri ile TamcotSphinx X Tamcot22 (hat no: 31 ) melezinde, en kaba lif ise 5.3 mic değeri ile BA-308 x Carmen (hat no: 52) melezinde görülmüştür. Kontrol çeşitler arasında Gloria ve Candia 4.7 mic. değeri ile en ince lif değerine sahip olduğu tespit edilmiştir. Kısıtlı sulama koşullarında ise en ince lif 4.2 mic. değeri ile BA-308 x DPL-90 (hat no: 77) ve Nazilli-503 X Tamcot22 (hat no. 46) melezlerinde, en kaba lif ise 5.2 mic değeri ile Ş-2000 x Tamcot22 (hat no: 90) melezinde görülmüştür. DP332 çeşidi 4.8 mic. değeri ile en ince life sahip kontrol çeşit olmuştur. Yapılan çalışma sonucunda 10 adet genotipin daha ince lifler üretebildiği saptanmıştır.

Pamuk döl sıralarının genel ortalamaları karşılaştırıldığında; kısıtlı sulama uygulamasının lifi \%4 kalınlaştırdığı belirlenmiştir. Çalışmaya paralel şekilde birçok araştırmacı (Dağdelen ve ark., 2009, Pettigrew, 2004, Balkcom ve ark., 2006; Zhang ve ark., 2016) yaptıkları çalışmalarında su stresinin mikroner değerini arttırdığını bildirmiştir. Snowden ve ark. (2013), yaptıkları çalışmalarında; normal bir yılda kuraklık stresi uygulandığında mikroner değerinin arttığını; sıcak bir yılda kuraklık stresi uygulandığında ise azaldığını bildirmiştir. Wang ve ark. (2016), yaptıkları çalışmalarında ise; \%45 kısıtlı sulama koşullarında mikroner değerinin azaldığını; \%60 kısıtlı sulama koşullarında ise arttığını; Lokhande ve Reddy (2014) ise mikroner değerinin optimum sıcaklık koşullarında yaprak suyu potansiyelindeki azalma ile arttığını, ancak optimum sulama koşullarında, mikroner değerinin $26{ }^{\circ} \mathrm{C}^{\prime}$ ye kadar sıcaklıklarla artıp daha yüksek sıcaklıklarda düştüğünü bildirmişlerdir. Hu ve ark. (2018a), çiçeklenme ve koza gelişimi dönemindeki su stresinin 
kozadaki lif sayısını ve lif uzunluğunu düşürdüğünü buna karşın lif kalınlık (microner) değerini arttırdığını ortaya koymuştur.

\section{SONUÇ}

Yapılan çalışma sonucunda; tam sulama koşullarında Carmen x Nazilli-503 (hat no: 1), DPL-90 x Tamcot-22 (hat no: 10), BA-308 x Carmen (hat no: 38), DPL-90 x Tamcot-22 (hat no: 66) ve ST-373 x DPL-90 (hat no: 72 ) ileri pamuk hatlarının verim ve lif kalite özellikleri bakımından öne çıktığı tespit edilmiştir. Kısıtlı sulama koşullarında ise Nazilli$503 \times$ Tamcot-22 (hat no: 6), ST-373 x Carmen (hat no: 23), BA-308 x Nazilli-503 (hat no: 47), BA-308 x Carmen (hat no: 72) ve $\$-2000 \times$ Tamcot-22 (hat no: 90) ileri pamuk hatlarının su stresine dayanıklı veya tolerant olduğu saptanmıştır. Tam ve kısıtlı sulama koşullarına uygun, verim ve lif kalitesi yüksek yeni pamuk çeşitlerinin tescil edilmesi amacıyla seçilmiş ileri pamuk hatları çeşit verim denemelerine alınacaktır.

\section{TEŞEKKÜR}

Bu çalışmanın yürütülmesinde maddi desteklerinden dolayı Adnan Menderes Üniversitesi Bilimsel Araştırma Projeleri Birimine Teşekkür ederiz (Proje Kodu: ZRF-18028).

\section{KAYNAKLAR}

Asadi R, Kohi N, Tavassoli A (2011) Effect of Irrigation Regime and Method of Strip Irrigation System on Yield, Yield Components and Water Use Efficiency of Cotton under Drought Stress Conditions of Orzouiyeh Region of Kerman Province in Iran. Scientific Research and Essays 6(27): 5812-5819.

Babb VM, Haigler CH (2001) Sucrose Phosphate Synthase Activity Rises in Correlation with High-rate Cellulose Synthesis in Three Heterotrophic Systems. Plant Physiology 127: 1234-1242.

Balkchom KS, Reeves DW, Shaw JN, Burmester CH, Curtis LM (2006) Cotton Yield and Fiber Quality From Irrigated Tillage Systems in The Tennessee Valley. Agronomy Journal 98: 596-602.

Barnabás B, Jäger K, Fehér A (2008) The Effect of Drought and Heat Stress on Reproductive Processes in Cereals. Plant, cell and environment 31(1): 11-38.

Basal H, Dagdelen N, Unay A, Yılmaz E (2009) Effects of Deficit Drip Irrigation Ratios on Cotton (Gossypium hirsutum L.) Yield and Fiber Quality. Journal of Agronomy and Crop Science 195: 19-29.

Bayraç HN, Doğan E (2016) Türkiye'de İklim Değişikliğinin Tarım Sektörü Üzerine Etkileri. Eskişehir Osmangazi Üniversitesi iiBF Dergisi, 11(1): 23-48.

Bota J, Medrano H, Flexas J (2004) Is Photosynthesis Limited by Decreased Rubisco Activity and RuBP Content under Progressive Water Stress. New Phytologist 162(3): 671-681.

Cave J (2013) Cotton Lint Yield, Fiber Quality, and WaterUse Efficiency As Influenced by Cultivar and Irrigation Level. Master of Sciences, Texas Tech University, USA.

Dağdelen N, Başal H, Yılmaz E, Gürbüz T, Akçay SM (2009) Different Drip Irrigation Regimes Affect Cotton Yield, Water Use Efficiency and Fiber Quality in Western Turkey. Agricultural Water Management 96: 111-120.
GÖREN HK, BAŞAL H

Ertek A, Kanber R (2003) Effects of Different Drip Irrigation Programs on The Boll Number and Shedding Percentage and Yield of Cotton. Agricultural Water Management 60: 1-11.

Gao M, Snider J, Bai H, Hu W, Wang R, Meng Y, Zhou Z (2020) Drought Effects on Cotton (Gossypium hirsutum I.) Fibre Quality and Fibre Sucrose Metabolism during The Flowering and Boll-Formation Period. J Agro Crop Sci. 2020 (00): 1-13.

Gerik TJ, Faver KL, Thaxton PM, El-Zik KM (1996) Late Season Water Stress in Cotton: I. Plant Growth, Water Use and Yield. Crop Science 36: 914-921.

Guinn G, Mauney J (1984) Fruiting of Cotton. II. Effects of Plant Moisture Status and Active Boll Load on Boll Retention. Agron. J. 76: 94-98.

Hu W, Snider JL, Wang H, Zhou Z, Chastain DR, Whitaker J, Bourland FM (2018a) Water-Induced Variation in Yield and Quality Can Be Explained by Altered Yield Component Contributions in Field-Grown Cotton. Field Crops Research 224: 139-147.

Hu W, Loka DA, Fitzsimons TR, Zhou Z, Oosterhuis DM (2018b) Potassium Deficiency Limits Reproductive Success by Altering Carbohydrate and Protein Balances in Cotton (Gossypium hirsutum L.). Environmental and Experimental Botany 145: 8794.

Hussein F, Janat M, Yakoub A (2011) Assessment of Yield and Water Use Efficiency of Drip Irrigated Cotton (Gossypium hirsutum L.) as Affected by Deficit Irrigation. Turkish Journal of Agrıculture and Forestry 35: 611-621.

IPCC (2013) Climate Change 2013: The Physical Science Basis. Contribution of Working Group I to the Fifth Assessment Report of the Intergovernmental Panel on Climate Change. Cambridge UniversityPress, Cambridge, United Kingdomand New York, USA.

Kadıoğlu M, Ünal Y, İlhan A, Yürük C (2017) Türkiye'de İklim Değişikliği ve Tarımda Sürdürülebilirlik, Türkiye Gıda ve İçecek Sanayi Dernekleri Federasyonu, http://www.hidropolitikakademi.org/wpcontent/uplo ads/2017/11/lklimDegisikligiRaporumin.pdf, (Erişim Tarihi: 23.01.2020).

Karademir Ç, Karademir E, Gençer O (2011) Yield and Fiber Quality of $F_{1}$ and $F_{2}$ Generations of Cotton (Gossypium hirsutum L.) Under Drought Stress Conditions. Bulgarian Journal of Agricultural Science 17: 795-805.

Kloth RH, Turley RB (2010) Physiology of seed and fiber development. Physiology of cotton, Springer, Dordrecht.

Lokhande S, Reddy KR (2014) Reproductive and Fiber Quality Responses of Upland Cotton to Moisture Deficiency. Agron. J. 106: 1060-1069.

McWilliams D (2004) Drought Strategies for Cotton. Cooperative Extension Service Circular 582 College of Agriculture and Home Economics http://www.cahe.nmsu.edu/pubs/circulars (Erişim Tarihi: 15.10.2011). 
McMichael BL, Hesketh JD (1982) Field Investigations of The Response of Cotton to Water Deficits. Field Crops Research 5: 319-333.

Mert M (2005) Irrigation of Cotton Cultivars Improves Seed Cotton Yield, Yield Components and Fibre Properties in The Hatay Region, Turkey. Acta Agriculturae Scandinavica, 55: 44-50.

Ulu B, Başal H (2018) $\mathrm{F}_{3}: 6$ Generasyonunda Pamuk (Gossypium hirsutum L.) Döl Sıralarının Tam ve Kısıtlı Sulama Koşullarında Verim ve Lif Kalite Özelliklerinin Belirlenmesi. Adnan Menderes Üniversitesi Ziraat Fakültesi Dergisi, 15(1): 65-71.

Parida AK, Dagaonkar VS, Phalak MS, Umalkar GV, Aurangabadkar LP (2007) Alterations in Photosynthetic Pigments, Protein and Osmotic Components in Cotton Genotypes Subjected to ShortTerm Drought Stress Followed by Recovery. Plant Biotechnology Reports 1(1): 37-48.

Papastylianou P, Argyrokastritis I (2014) Effect of Limited Drip Irrigation Regime on Yield, Yield Components and Fiber Quality of Cotton Under Mediterranean Conditions. Agricultural Water Management 142: 127-134.

Petersen RG, Calvin LD (1965) Methods of Soil Analysis. Agron. Monogr. 9: 54-72.

Pettigrew WT (2001) Environmental Effects on Cotton Fiber Carbohydrate Concentration and Quality. Crop Science 41: 1108-1113.

Pettigrew WT (2004) Moisture Deficit Effect on Cotton Lint Yield, Yield Components and Boll Distribution. Agronomy Journal 96: 377-383.

Pettigrew W, Gerik T (2007) Cotton Leaf Photosynthesis and Carbonmetabolism. Adv. Agron 94: 209-236.

Price K (2009) Investigation of Methods to Evaluate Drought Toerance in Cotton. The Degree of Doctor of Philosopy, Texas Tech University, Texas Lubbock, USA.
Rai E (2011) Mechanism of Drought Tolerance in CottonResponse of Cotton Cultivars to Irrigation in The Texas High Plains. Master of Science, Texas Tech University, USA.

Shareef M, Gui D, Zeng F, Ahmed Z, Waqas M, Zhang B, Fiaz $M$ (2018) Impact of Drought on Assimilates Partitioning Associated Fruiting Physiognomies and Yield Quality Attributes of Desert Grown Cotton. Acta Physiologiae Plantarum 40(4): 71.

Snowden C, Ritchie G, Cave J, Keeling W, Rajan N (2013) Multiple Irrigation Levels Affect Boll Distribution, Yield, and Fiber Micronaire in Cotton. Agronomy Journal 105: 1536-1544.

Şahin A (2000) Melezleme Islahı ile Kuraklığa Dayanıkı Pamuk Çeşitlerinin Geliştirilmesi. Pamuk Araştırma İstasyonu Müdürlüğü Yayınları. Nazilli.

Tang F, Zhu J, Wang T, Shao D (2017) Water Deficit Effects on Carbon Metabolism in Cotton Fibers during Fiber Elongation Phase. Acta physiologiae plantarum 39(3): 69.

Wang R, Gao M, Ji S, Wang S, Meng Y, Zhou Z (2016) Carbon Allocation, Osmotic Adjustment, Antioxidant Capacity and Growth in Cotton under Long-Term Soil Drought During Flowering and Boll-Forming Period. Plant Physiology and Biochemistry 107: 137-146.

Zhang WJ, Shu HM, Hu HB, Chen BL, Wang YH, Zhou ZG (2007) Genotypic Differences in Some Physiological Characteristics During Cotton Fiber Thickening and Its Influence on Fiber Strength. Acta Agronomica Sinica 31: 927-935.

Zhang D, Luo Z, Liu S, Li W, Dong H (2016) Effects of Deficit Irrigation and Plant Density on The Growth, Yield and Fiber Quality of Irrigated Cotton. Field Crops Research 197: 1-9. 